\title{
Injuries and violence in the Eastern Mediterranean Region: a review of the health, economic and social burden
}

\author{
Abdulgafoor M. Bachani, ${ }^{1}$ Xiaoge Julia Zhang, ${ }^{7}$ Katharine A. Allen ${ }^{7}$ and Adnan A. Hyder ${ }^{7}$
}

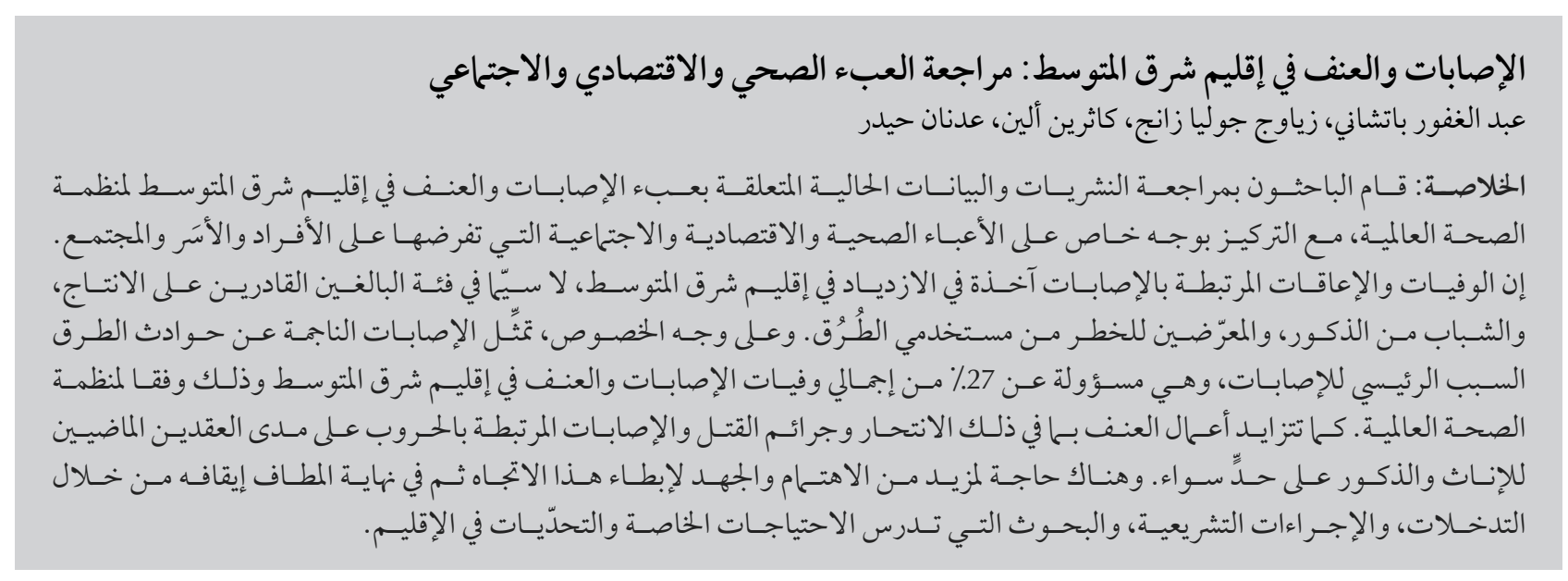

ABSTRACT We review current literature and data on the burden of injury and violence in the Eastern Mediterranean Region (EMR) of the World Health Organization (WHO), with a special focus on the health, economic and social burden they impose on individuals, families and society. Injury-associated mortality and disability is on the rise in EMR, especially among economically productive adults, young males and vulnerable road users. In particular, road traffic injuries, the leading cause of injuries, account for $27 \%$ of the total injury and violence mortality in EMR according to WHO. Violence including suicide, homicide and war-related injury has also been increasing over the past two decades for both females and males. There is need for greater interest and efforts in slowing and ultimately halting the trend through interventions, legislative actions, and research that examine the special needs and challenges in the Region.

Traumatismes et violence dans la Région de la Méditerranée orientale : examen de la charge sanitaire, économique et sociale

RÉSUMÉ Nous avons passé en revue la littérature actuelle ainsi que les données relatives à la charge des traumatismes et de la violence dans la Région OMS de la Méditerranée orientale, en accordant une attention particulière à la charge sanitaire, économique et sociale que ceux-ci imposent aux individus, aux familles et à la société. La mortalité et l'incapacité liées aux traumatismes sont en augmentation dans la Région de la Méditerranée orientale, en particulier chez les adultes économiquement productifs, les hommes jeunes ainsi que les usagers de la route vulnérables. Plus particulièrement, les traumatismes dus aux accidents de la circulation, qui constituent la principale cause de traumatismes, représentent, selon l'OMS, 27 \% de la mortalité totale due aux traumatismes et à la violence dans la Région. La violence, notamment les suicides, les homicides et les traumatismes liés à la guerre, a également augmenté au cours des vingt dernières années chez les hommes et les femmes. Il est nécessaire de susciter un plus grand intérêt quant à ces questions et de redoubler d'efforts en vue de ralentir ces tendances à la hausse et à terme, d'arrêter leur progression par le biais d'interventions, de mesures législatives et de la recherche qui s'attachent à déterminer les besoins spéciaux ainsi que les défis de la Région. 


\section{Introduction}

The World Health Organization (WHO) estimates that globally every 5 seconds a human life is cut short as a result of an injury (1). Estimates from the Global Burden of Disease (GBD) study show that in 2010 more than 3.5 million individuals died as a result of unintentional injuries (2). Additionally, millions more often survive but are disabled, accounting for 202 million disability-adjusted life years (DALYs) in 2010 (3). Road traffic crashes are the leading cause of unintentional injuries, and are estimated to contribute to more than 3600 deaths on the world's roads every day (3). Moreover, they account for nearly a quarter of all injury and violence-related deaths globally (Figure 1). Estimates from $\mathrm{WHO}$ suggest that road traffic injuries (RTIs) will become the fifth leading cause of death by 2030 unless action is taken to curb this growing epidemic (4).

Violence that causes intentional injuries including self-harm, interpersonal violence and war-related injuries account for another one-third of the mortality due to injury and violence globally (Figure 1), totalling about 1.4 million deaths in 2012 and marginally down from 1.5 million in 2000 (5). Over half of these deaths were suicides, and nearly one-third were homicides. Similar to RTIs, suicide and homicide are predicted to rise in the ranking to become the 12th and 18th leading causes of death, respectively, in the world by 2030 (1). Both injury and violence burden disproportionately affect low- and middle-income countries where $90 \%$ of the global burden lies $(6,7)$.

In this paper, we aim to highlight the burden of injury and violence in the WHO Eastern Mediterranean Region (EMR) within the broader context of the global burden of injury and violence. We focus specifically on the health, economic and social burden that injury and violence impose on individuals, families, and society. Effective interventions that target the major risk factors and the economic evidence of the interventions are also included. This review presents the progress made in the past two decades in reducing and preventing the burden of injury and violence globally and in EMR while highlighting the persistent challenges that need to be overcome.

The regional comparative evidence in this review is based upon data from the six WHO regions: Region of the Americas, African Region, EMR, European Region, South-East Asia Region, and Western Pacific Region. Other global and regional mortality and morbidity estimates for injury and violence are based on estimates from the Global Burden of Disease Study (GBD), which has different regional divisions from those of WHO (3). The GBD region that is defined most similarly to EMR is the North Africa and Middle East region. ${ }^{1}$

\section{Health burden of injuries \& violence in EMR}

The Region is facing a similar trend of growing burden of injuries. According to 2012 WHO estimates, injuries and violence rank as a leading cause of death, contributing to approximately $12 \%$ of total deaths in EMR (5). The fraction of mortality caused by injuries and violence in EMR is higher than the global distribution (9\%), which is primarily attributable to a greater proportion of

\footnotetext{
GBD's North Africa and Middle East region includes Algeria and Turkey, which are not members of EMR, and does not include Djibouti, Somalia or Sudan, which are EMR countries. Despite different methodologies and definitions of the region employed by GBD and $\mathrm{WHO}$, we present both data here because each source has its own unique method that complements the other. For example, the GBD study offers more data on DALYS and deaths by type of injury and demographic characteristics, while WHO data provide better comparative analyses across WHO regions.
}

RTI deaths in EMR (3\%) as compared to the global estimate (2\%). When examining the distribution of injury deaths by cause, the proportion of injury and violence deaths due to RTIs in EMR (27\%) is slightly higher than the global proportion (24\%) (Figure 1). While other leading causes of unintentional injury, including drowning, burns and poisonings, are responsible for similar fractions of regional mortality as the global distribution, the proportion of deaths caused by falls in EMR was only a third of the global estimate (5\% vs. $14 \%)$.

For deaths due to violence, the fraction of homicides is marginally smaller than the global estimate, while suicides are reported to be less than half of the global figure (6\% vs. 17\%). These differences might be attributed in part to more conservative sociocultural attitudes toward suicide and homicide in the Region (8). However, the proportion of collective violence in the Region is more than 10-fold greater than that of global estimates ( $21 \%$ vs. $2 \%$ ). Given the recent increase in collective violence in countries like the Syrian Arab Republic and Iraq, these numbers reflect growing sociopolitical instability in EMR.

The EMR of WHO comprises 21 Member States and the occupied Palestinian territory (West Bank and Gaza Strip), spanning countries from North Africa to western Asia with a population of nearly 583 million (9). Within the Region, the burden of injuries and violence differs across countries and reflects the unique set of geographic, social and economic characteristics of each country (10). For example, the high-income Gulf Cooperation Council countries such as Saudi Arabia have a rising burden of road injuries, due to a multitude of factors including an influx of expatriates who are unfamiliar with local driving conditions and laws, insufficient focus on public transport, increase in the number of vehicles and inadequate planning of road infrastructure $(11,12)$. In low- and middle-income countries, 
Global, 2012

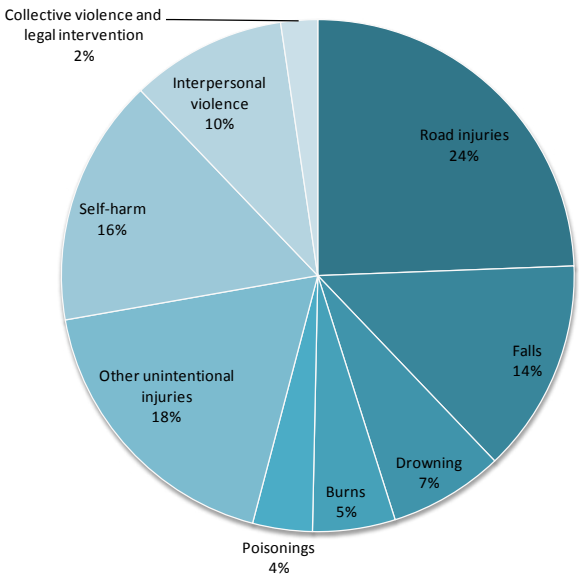

Eastern Mediterranean Region, 2012

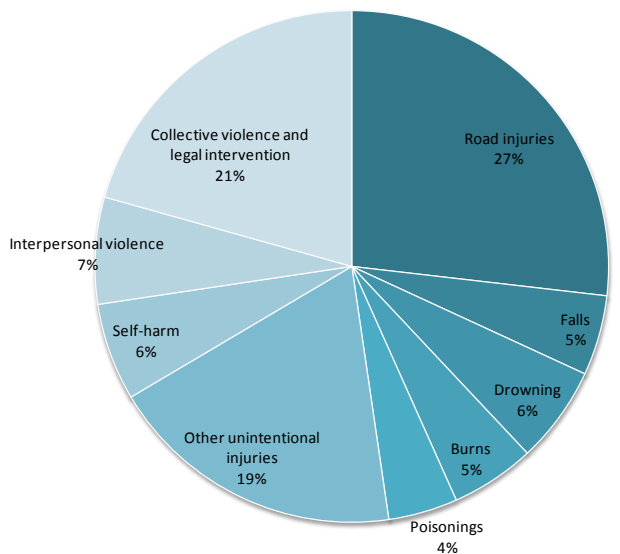

Figure 1 Injury deaths by cause globally and in the Eastern Mediterranean Region of the World Health Organization, 2012 [Source: Global health estimates 2014 summary tables: Deaths by cause, age and sex, by WHO region, 2000-2012. Geneva, World Health Organization, June 2014 (http://www.who.int/healthinfo/global_burden_disease/en/, accessed 12 August 2014)]

injuries due to collective violence pose a significant burden in countries like the Syrian Arab Republic, Iraq and Yemen (13-15). Despite such differences, when compared to other WHO regions, EMR has the third highest mortality rate for injuries and violence at 81 per 100000 (5) (Figure 2). According to WHO, in 2012 about half a million people in EMR died as a result of injuries and violence (5). In terms of death and disability, they resulted in 33 million DALYs lost (16).

Estimates by WHO show that in 2012 RTIs were responsible for more than 133000 deaths and 8.5 million DALYs lost in the Region (5). In contrast, 2010 estimates produced by the GBD for the North Africa and the Middle East Region indicate that RTIs accounted for 78000 deaths and 4.8 million DALYs lost (3). Such differences highlight contrasting methodological approaches in deriving these estimates, but still illustrate the large burden of RTIs in the Region $(3,5)$. While EMR does not have the highest overall injury mortality rate, it has the second highest RTI-related mortality rate at 21.8 per 100000 (Figure 2). This is only slightly lower than the African region, with a rate of 22.5 per 100000 (5) (Figure 2).

While there are no definite data on the number of people who survive injury or violence with some form of permanent disability, estimates suggest that for every RTI-related death between 20 and 50 more individuals suffer some form of disability (17). For every young person killed by violence, an estimated 20-40\% more have injuries that require hospitalization (7). According to $\mathrm{WHO}$, in 2012 unintentional injuries accounted for a total of 44.8 million years lost due to disability, while violence and self-harm accounted for 2.1 million - together they represent 6.3\% of the total global burden of disability (18).

Further, WHO estimates show that EMR loses about 3.5 million and 200000 life years annually due to disability caused by unintentional injuries and intentional injuries, respectively (18). This burden, in terms of both premature mortality and disability, is significant and is partly attributable to the fact that young adults, between ages of 15 and 44 years, are among the most affected (Figure 3) (5). When examining the distribution of injury deaths by age-group, 15-44-year-olds account for almost $40 \%$ of all unintentional injury deaths and $70 \%$ of all self-harm and violence-related mortality as a proportion of the total injury deaths (5). These young and economically productive individuals may lose the capacity to work depending on the severity of injury. In particular, moderate to severe injury and violence often require expensive inpatient care and long-term rehabilitation, which exacerbates the economic burden on individuals, families and society.

RTIs, for example, are the leading cause of death for individuals aged 19-25 years worldwide, with almost 400000 young people under the age of 25 years dying from road traffic crashes each year - this translates into about 1049 persons a day $(19,20)$. More than three-quarters of these deaths occur among young males, with rates of both injury death and DALY loss being much higher among males than females $(5,16)$. The vulnerability of young males to RTIs is especially alarming in EMR where more than $75 \%$ of all RTI-related deaths are males (5). A recent study 


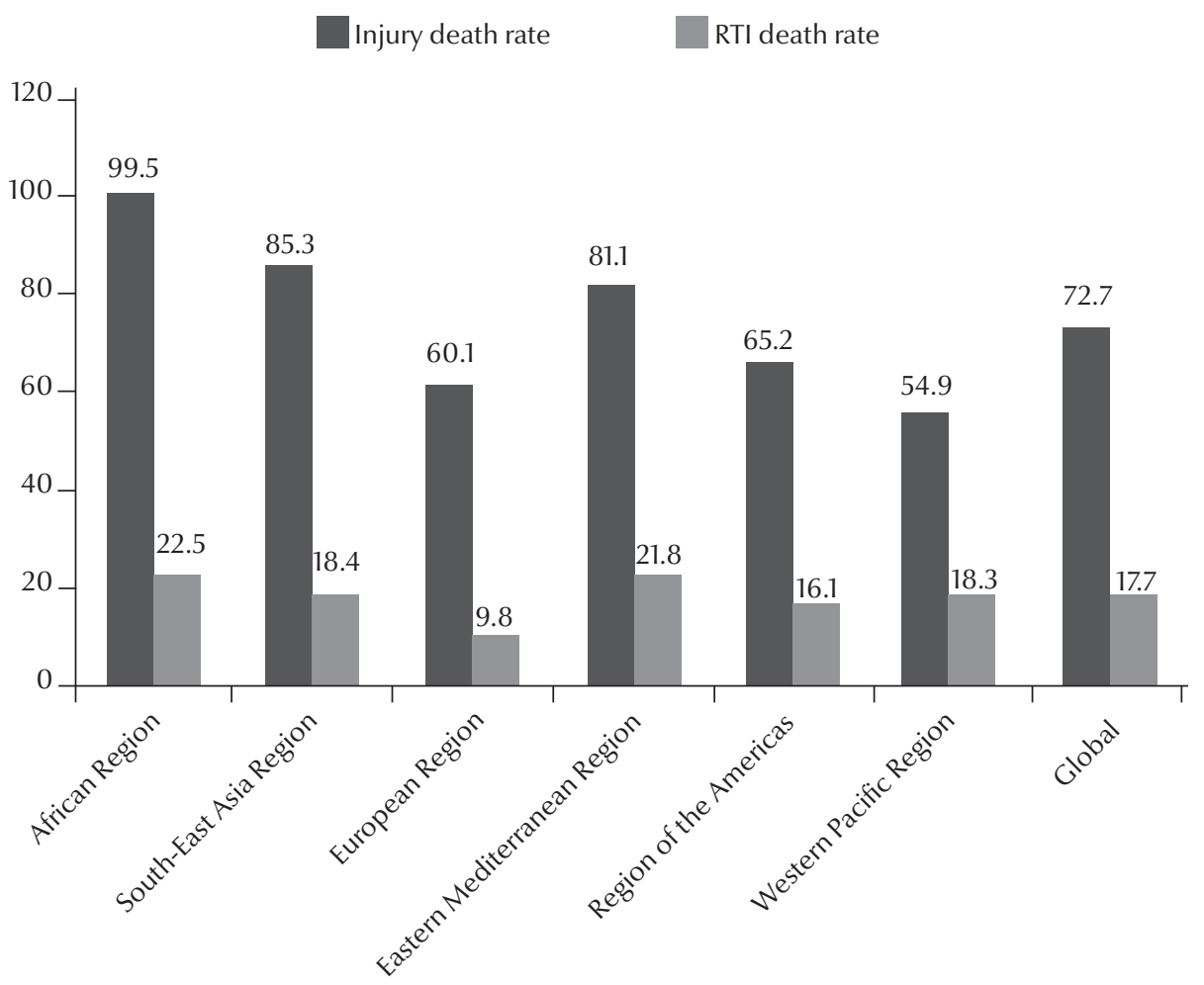

Figure 2 Mortality per 100000 population from injuries and violence compared to road traffic injuries (RTIs) by World Health Organization region, 2012 [Source: Global health estimates 2014 summary tables: Deaths by cause, age and sex, by WHO region, 2000-2012. Geneva, World Health Organization, June 2014 (http://www.who.int/healthinfo/global_burden_ disease/en/, accessed 12 August 2014)]

from Qatar further illustrates the high burden of RTIs among young males in EMR. Young Qatari males between the ages of 10 and 29 years have a RTI mortality rates that are 5-10 times higher than those experienced by the general population (21). To put this into further perspective, young Qatari males have an RTI death rate that is 5.4 times higher than that of similarly aged males in the United States (21).

Another critical factor responsible for the high burden of RTIs in EMR is the large proportion of vulnerable road users in the Region ranging from 30\% in the middle-income countries, to $40 \%$ in the high-income countries, to more than $70 \%$ in the low-income countries (22). WHO defines vulnerable road users as pedestrians, cyclists and motorcyclists, who, when compared to motor vehicle occupants, are at greater risk of RTIs and more likely to bear the greatest burden of injury (17). At the global level, half of all road traffic deaths occur among these vulnerable road users - motorcyclists (23\%), pedestrians (22\%) and cyclists (5\%) (4). In EMR, there are few, if any, interventions in place to protect these vulnerable road users, which according to the WHO's 2013 Global Status Report on Road Safety account for $45 \%$ of all road injury fatalities (pedestrians (28\%), motorcyclists (14\%) and cyclists (3\%)) (4). Additionally, this distribution of RTIs among vulnerable road users varies by countries within the Region. For example, among most of the high-income Gulf countries of EMR, occupants of four-wheel vehicles account for the vast majority of RTI deaths, whereas in middle-income countries, such as Morocco and Tunisia, pedestrians and those on motorized two and three-wheel vehicles are responsible for the majority of deaths (23).

Injuries and violence are also unevenly distributed between males and females. While there has been reduction in the unintentional injury mortality rate globally and in EMR over the past decade (5), the fact remains that almost twice as many men as women die as a result of unintentional injuries each year (1). The GBD study offers trend data and shows that RTIs, in particular, have been steadily rising and were the 2 nd leading cause of DALY loss for men in the North Africa and Middle East region in 2010, up from the 7th in 1990 (3). Some types of injuries, however, predominantly affect women. For example, women have a higher rate of injuries resulting from burns than males, with this difference particularly pronounced among adolescents aged 15-19 years in the low- and middle-income countries of EMR (1). A systematic review of burn injuries in EMR found that in certain countries such as the Islamic Republic of Iran, self-inflicted burns were more common among females and were associated with a 
mortality rate of up to $79 \%$ (24). Additionally, domestic violence against women remains an issue in EMR with a 2012 study from Alexandria, Egypt showing that $59 \%$ of all rural women reported being exposed to domestic violence at least once during their marriage (25). Similarly, a 2011 survey in Jordan found the lifetime prevalence of domestic abuse to be 30\% among women (26). Recent WHO estimates also confirm that EMR has the second highest prevalence of physical and/ or sexual intimate partner violence among ever-partnered women (37\%) compared to other WHO regions (27). It is important to note that while GBD data show that there has been a decline, albeit marginal, in the rate of fatalities due to violence over the last two decades (20.2/100 000 in 1990 to $19.6 / 100000$ in 2010) globally, it has been growing in the North African and Middle East region for both males and females (4). This is likely due to a number of protracted conflicts that have affected roughly $85 \%$ of the population in the Region over the past two decades including such countries as Iraq, Afghanistan, Libya and more recently the Syrian Arab Republic (28).

These conflicts have killed a large number of combatants and non-combatants; however, a significant number of injuries have also arisen due to the collapse of the local infrastructure $(14,29)$. In Iraq, a national cross-sectional study revealed that a large portion of injuries is attributable to the breakdown of local and regional infrastructure due to ongoing conflict (29). Such injuries include those from electric shock, unintentional explosions and falls; this highlights the overlooked burden of injuries that result from damaged and destroyed infrastructure.

\section{Economic burden of injuries and violence}

In addition to the health burden, injuries and violence also account for profound economic costs at the individual, familial and societal level. In an environment with scarce resources, assessing injury- and violence-related costs helps policy-makers and health planners prioritize and choose the most appropriate interventions to control and prevent injuries and violence (30). However, accurately quantifying these costs is difficult. For example, the tangible costs of injuries or violence - such as direct costs (medical or mental health care costs, legal and social services) and indirect costs (e.g., lost productivity and economic opportunity) - can be estimated in economic terms (30). But the intangible costs, for example, those associated with pain and suffering are not straightforward and often difficult to assess (30).

Due to a high demand for epidemiological data on the number and nature of different types of injuries, as well as the aforementioned methodological challenges, few studies have attempted to estimate the costs of all

Unintentional injury Intentional injury

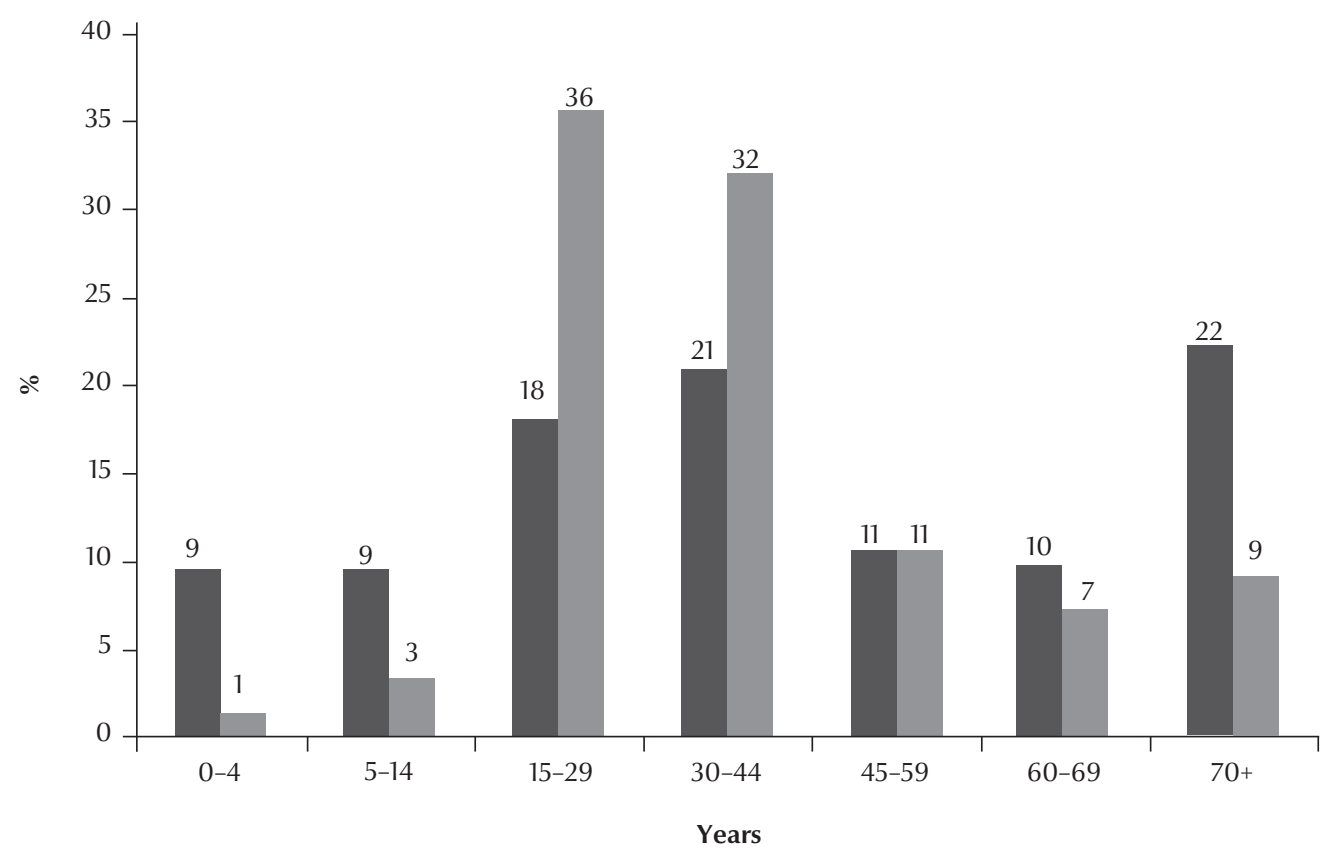

Figure 3 Intentional and unintentional injury mortality in the Eastern Mediterranean Region by age group, 2012 [Source: Global health estimates 2014 summary tables: Deaths by cause, age and sex, by WHO region, 2000-2012. Geneva, World Health Organization, June 2014 (http://www.who.int/healthinfo/global_burden_disease/en/, accessed 12 August 2014)] 
injuries. Among all types of injuries, RTIs have been the focus of the largest proportion of cost studies, likely because RTIs are the most common type of injury and have the best available data, compared to other injuries. One large 21-country study estimated the global cost of RTIs worldwide to be US $\$ 518$ billion, while the costs of RTIs at the national level generally exceed $1 \%$ of a country's gross national product (GNP) (31). Studies in the United States, European Union and Australia have also highlighted the significant burden on the economy that road traffic crashes impose (32-34). A more recent analysis of the cost of RTIs conducted by WHO reveals a greater economic burden of RTIs as a share of the gross domestic product (GDP) in EMR, ranging from $1.6 \%$ in Jordan to $4 \%$ in Kuwait (4). Another recent study examining the economic costs of RTIs in Egypt found that they amount to about US\$ 427 million annually in terms of property losses, lost productivity and medical costs (30). Similarly, a study in the Islamic Republic of Iran estimates that the total cost of road traffic crashes during the one-year study period was US\$ 7.2 billion, which amounts to $2.2 \%$ of the country's GDP. Of the total cost, almost half was spent on medical services followed by $34 \%$ on productivity losses (35).

Cost studies on injuries are often scant in low- and middle-income countries due to the poor capacity of health information systems to capture reliable data (4). Estimates show that RTIs in low- and middle-income countries cost approximately US\$ 65 billion, or 1-2\% of a country's GNP (31). The high RTI-related costs as a share of GNP have also been shown in a few country-specific studies including Bangladesh (36), Uganda (37), Eastern Europe (38) and China (39).

Most cost studies on violence are found in the high-income countries likely due to the fact that their health care, legal and social welfare systems are more developed and prepared to care for victims of violence. In the United States, for example, intimate partner violence, physical assault and stalking cost over US\$ 5.8 billion each year, nearly US\$ 4.1 billion for direct medical and mental health services and US\$ 0.9 billion on lost productivity (40). Similarly in France, it has been estimated that intimate partner violence costs approximately 2.5 billion Euros per year, accounting for costs of health, social and justice services, and productivity losses among others (41). A systematic review on the costs of intimate partner violence in Germany also speaks to the substantial extent of the associated economic burden (42).

The high cost of violence, however, is not unique to high-income countries. WHO estimates show that the economic costs of homicide and suicide were equivalent to $1.2 \%$ of GDP in Brazil, 4\% of GDP in Jamaica, and $0.4 \%$ of GDP in Thailand (1). A crosssectional study in Nepal also highlights the substantial economic (US\$ 126 for a single injury case) and social burden of injuries and violence (43). While these studies clearly demonstrate a significant burden of injuries and violence, more studies are needed to determine and understand the full extent and nature of this burden. For example, available evidence shows that when compared to those without a history of abuse, victims of domestic and sexual violence have both more and longerterm health problems; they incur significantly higher health care costs due to more frequent visits to emergency departments and mental health facilities throughout their lives (44). In addition, children who are victims of maltreatment face more persistent economic deprivation due to the required long-term treatment for mental illnesses and possible chronic diseases (45). Taking into account these longterm and recurring health care costs when estimating the economic burden would reveal a clearer picture of the true burden.

\section{Social and long-term impact of injuries and violence}

While tremendous progress has been made in understanding the epidemiology of injuries and violence and some on the economic burden, understanding the long-term impact of injuries and violence remains a significant research gap. In low- and middle-income countries, in particular, because of the scarcity of good medical and mental health or rehabilitation services and lack of financial protection mechanisms, individuals often rely heavily on social networks for support. In these settings, injuries and violence often have far reaching implications, which need to be understood to better address the burden.

Studies examining the social impact of injuries in low- and middle-income countries are almost nonexistent (17). However, those that do exist show that road traffic crashes and resultant death or disability can place a heavy toll on the family and friends of the injured person, many of whom experience adverse financial, physical, social and psychological stress. For example, families and friends of the injured reallocate work or change work pattern to take care of the injured person. Often debts are incurred because of the expensive rehabilitation services and reduced income (46). Children in these households can be pressured to leave school or suffer from decreased supervision. To illustrate how road traffic crash injuries affect families in EMR, a 2010 study from the Gaza Strip in Palestine showed that the majority of all traumatic brain injuries were due to RTIs. As a result, over $60 \%$ of the caregivers of these injured individuals were mothers, with the majority stating their care-giving activities deprived them of community 
involvement (47). Additionally, these mothers were unable to work or engage in other economically productive activities outside of the home (47).

The impact of violence extends far beyond the economic burden to families and communities; the pain and suffering of violence can have a lasting impact on human and social development $(7,48)$. Studies in the United States France, Germany and Nepal on the societal costs of violence indicate that communities and societies are affected by violence through the loss of social cohesion, financial divestment and an increased burden on the health care and justice systems (40-43). These effects extend to the individual level as well. For example, a 2010 study from Lebanon showed that almost half of all adolescents injured during the 1975-1990 civil war failed to continue their schooling while $42 \%$ of working individuals lost their jobs as a result of their injuries (49).

\section{Addressing the burden of injuries and violence}

Most injury and violence deaths can be prevented since the risk factors involved largely predict their occurrence. While the risk factors related to injury and violence are complex and multifactorial, there are many counter-measures targeting the risk factors of injury and violence that have been shown to be effective in a variety of settings $(48,50,51)$. Interventions not only can help lower fatalities and DALY losses caused by injury and violence, they also have obvious economic benefits. They reduce direct costs on medical, social and legal services associated with injury and violence as well as the indirect costs of lost productivity and economic opportunities. However, data on the economic benefits of these interventions, especially those related to violence prevention or those in low- and middle-income countries, are limited.
A recent systematic review on the costs, cost-effectiveness and economic benefits of interventions for injury and violence in low- and middle-income countries found that of 68 economic evaluations on injury and violence, only 13 cost-effectiveness analyses, all on injury interventions, were published before February 2013 (52). The majority of the studies analysed the cost-effectiveness of interventions to reduce RTIs and drowning, and to improve pre-hospital and hospital-based trauma care. The authors applied the standards from the WHO-Choosing Interventions that are Cost Effective (WHO-CHOICE) project to compare interventions that report costs in terms of life years saved or DALYs averted (53). In this review, four economic evaluations modelled the cost-effectiveness of enforcement strategies related to RTIs in several lowand middle-income countries - better enforcement of general traffic codes, speed limit, random breath testing, use of seat belt and use of bicycle helmet and motorcycle helmet as well as enhanced traffic safety patrols, all of which yielded similar results showing that these interventions were very cost-effective (54-57). Specifically, costs per death averted were estimated to be US $\$ 30$ for enhanced traffic enforcement in urban Uganda and the cost per DALY averted from injury-prevention interventions ranged from US\$ 10.9 for speed bump installation to US\$ 17000 for legislation and enforcement of motorcycle helmets in the WHO's African Region $(54,56)$. The results also suggested that simultaneous implementation of multiple road safety enforcement campaigns would lead to the most health gain at the least expense (57). For example, Ditsuwan and colleagues found that implementing a mass media campaign and random breath testing together would potentially reduce the burden of alcohol-related RTIs by $24 \%$ in Thailand (57). The cost-effectiveness of a drowning prevention in rural Bangladesh was also assessed by Rahman and colleagues (58). They found that a preschool education system and a child swim programme to be very costeffective in preventing drowning among children (US\$ 362 per DALY averted) (58).

Compared to interventions for unintentional injuries, effective interventions for violence prevention are not widely implemented and there is even less information about their cost and/or cost-effectiveness. However, the existing literature, although varied in quality, indicates promising economic evidence for violence prevention, especially for intimate partner violence and violence among youth. For example, a randomized controlled trial of an intervention combining microfinance with gender and HIV training to reduce intimate partner violence in rural South Africa estimated that the intervention was cost-effective during both initial trial phase (US\$ 7688 per DALY averted) and scaling up (US\$2 307 per DALY averted) (59). Another Australian programme targeting female victims of intimate partner violence by providing education and support for primary care physicians to identify and refer potential victims to proper care yielded similar results (60). To reduce exposure to violence among youth, a United States retrospective cohort study delivered a hospital-based, peer intervention programme for disadvantaged youth. The results showed that when compared with juvenile detention centre costs, the total cost reduction derived from the intervention annually was US\$750 000 to US\$ 1.5 million (61).

While limited, these studies highlight the fact that interventions for preventing injuries and violence are cost-effective. In an environment of limited resources and competing priorities, such studies have been found to resonate with policy-makers and therefore it is imperative that more economic evaluations of interventions for other types of injury and violence be done in 
low- and middle-income countries to advance this important agenda.

\section{Conclusion}

The studies discussed in this paper illustrate that injuries and violence continue to significantly contribute to the health, social and economic burden in EMR. More specifically, in this region RTIs pose a significant challenge and have yet to be adequately addressed, despite the availability of proven and effective interventions. While RTIs remain an EMR-wide challenge, intra-region variations highlight the importance of understanding differing risk profiles across countries. As this paper has shown, the high-income Gulf countries have a larger proportion of four-wheel vehicles compared to two and three-wheeled vehicles in low- and middle-income countries within the region, which has an important effect on the nature of RTIs resulting from crashes. Quantifying these varying risk profiles is crucial to developing appropriate interventions, suggesting that a one-size-fits-all approach is not always applicable.
These differing risk profiles, which are highly correlated with country-income levels, highlight the growing effect of collective violence and the mounting burden of resultant injuries, which have had, and continue to have, a profound effect on low- and middle-income countries like Iraq, Afghanistan and the Syrian Arab Republic. This increased instability indicates that a concerted focus on such vulnerable countries will be critical in the coming years. By focusing on such trends, this paper attempts to provide a better understanding of the injury burden in the Region and serve to renew interest in slowing or even halting this trend.

However, this burden in EMR can only be addressed through the implementation of interventions and legislative action that addresses behavioural, environmental, vehicle/equipment and structural factors, as well as the availability of adequate post-injury care. Despite much knowledge on the effectiveness of injury prevention interventions in high-income countries, most studies have failed to assess the efficacy of these interventions in terms of low- and middle-income countries (50). Since the majority of countries in EMR are low- and middle-income countries, it is clear that more research is needed to better understand the specific needs in EMR, as well as policy and legislation frameworks that may be appropriate for such settings. While high-income countries in EMR may ostensibly have the funding base to implement such interventions, work is still lacking in this area. Part of this implementation gap may be due to the lack of adequate data systems to yield accurate and country-level estimates of this burden (62). Attention therefore needs to be paid to establishing systems that will yield the data necessary to inform these activities, as well as adequately trained human resources to both generate new research as well as design and implement the appropriate policies and programmes. Only with such a detailed roadmap will progress be made in reducing the burden of injuries and violence in EMR.

\section{Acknowledgement}

The authors thank Dr Hala Sakr, WHO Regional Office for the Eastern Mediterranean, for her in-depth review of the manuscript.

\section{References}

1. Injuries and violence: the facts. Geneva, World Health Organization, 2010 (http://whqlibdoc.who.int/publications/2010/9789241599375_eng.pdf?ua=1, accessed 26 April 2014)

2. Lozano R, Naghavi M, Foreman K, Lim S, Shibuya K, Aboyans $\mathrm{V}$, et al. Global and regional mortality from 235 causes of death for 20 age groups in 1990 and 2010: a systematic analysis for the Global Burden of Disease Study 2010. Lancet. 2012 Dec 15;380(9859):2095-128. PMID:23245604

3. Global Burden of Disease 2010. Institute for Health Metrics and Evaluation, 2013 (http://www.healthmetricsandevalua-

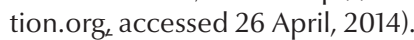

4. Global status report on road safety 2013: supporting a decade of action. Geneva, World Health Organization, 2013. (http:// www.who.int/violence_injury_prevention/road_safety_status/2013/report/en/, accessed 26 April 2014)

5. Global health estimates 2014 summary tables: Deaths by cause, age and sex, by WHO region, 2000-2012. Geneva, World Health Organization, June 2014. (http://www.who. int/healthinfo/global_burden_disease/estimates/en/index2. html, accessed 12 August 2014)

6. The injury chart book: A graphical overview of the global burden of injuries. Geneva, World Health Organization,
2002. (http://whqlibdoc.who.int/publications/924156220X. pdf?ua=1, accessed 26 April 2014)

7. 10 facts about the violence prevention. Geneva, World Health Organization, 2014. (http://www.who.int/features/factfiles/ violence/violence_facts/en/, accessed 26 April, 2014)

8. Rezaeian M. Suicide/homicide ratios in countries of the Eastern Mediterranean Region. East Mediterr Health J. 2008 NovDec;14(6):1459-65. PMID:19161122

9. About us. Cairo, World Health Organization regional office of Eastern Mediterranean, 2014 (http://www.emro.who.int/ entity/about-us/index.html, accessed 26 April, 2014)

10. Mandil A. Commentary: Mosaic Arab world, health and development. Int J Public Health. 2009;54(5):361-2, discussion 363-4. PMID:19834657

11. Ansari S, Akhdar F, Mandoorah M, Moutaery K. Causes and effects of road traffic accidents in Saudi Arabia. Public Health. 2000 Jan;114(1):37-9. PMID:10787024

12. Al-Naami MY, Arafah MA, Al-Ibrahim FS. Trauma care systems in Saudi Arabia: an agenda for action. Ann Saudi Med. 2010 Jan-Feb;30(1):50-8. PMID:20103958

13. Coutts A, McKee M, Stuckler D. The emerging Syrian health crisis. Lancet. 2013 Feb 9;381(9865):e6-7. PMID:23375240 
14. Levy BS, Sidel VW. Adverse health consequences of the Iraq War. Lancet.2013 Mar16;381(9870):949-58.PMID:23499043

15. Ager A, Blake C, Stark L, Daniel T. Child protection assessment in humanitarian emergencies: case studies from Georgia, Gaza, Haiti and Yemen. Child Abuse Negl. 2011 Dec;35(12):1045-52. PMID:22099145

16. Global health estimates 2014 summary tables: DALYs by cause, age and sex, by WHO region, 2000-2012. Geneva, World Health Organization, 2014. (http://www.who.int/healthinfo/ global_burden_disease/estimates/en/index2.html, accessed 12 August 2014)

17. Peden $\mathrm{M}$, et al., editors. World report on Road Traffic Injury Prevention. Geneva: World Health Organization; 2004. [cited 2014 April 26]. Available from: http://whqlibdoc.who.int/ publications/2004/9241562609.pdf?ua=1

18. Global health estimates 2014 summary tables: YLDs by cause, age and sex, by WHO region, 2000-2012. Geneva, World Health Organization, 2014. (http://www.who.int/healthinfo/ global_burden_disease/estimates/en/index2.html, accessed 12 August 2014)

19. Youth and road safety. Geneva, World Health Organization, 2007 (http://www.who.int/management/programme/ncd/ Youth\%20and\%20Road\%20Safety.pdf, accessed 26 April, 2014)

20. 10 facts on global road safety. Geneva, World Health Organization, 2013 (http://www.who.int/features/factfiles/roadsafety/facts/en/, accessed 26 April, 2014)

21. Consunji RJ, Peralta RR, Al-Thani H, Latifi R. The implications of the relative risk for road mortality on road safety programmes in Qatar. Inj Prev. 2014 Jan 28 [Epub ahead of print] PMID:24473538

22. Key facts of Global status report on road safety 2013: supporting a decade of action. Geneva, World Health Organization, 2013 (http://www.who.int/violence_injury_prevention/ road_safety_status/key_data/kd_2.pdf?ua=1, accessed 26 April, 2014)

23. Eastern Mediterranean status report on road safety: Call for action. Cario, WHO Regional Office for the Eastern Mediterranean. 2010.

24. Othman N, Kendrick D. Epidemiology of burn injuries in the East Mediterranean Region: a systematic review. BMC Public Health. 2010;10:83. PMID:20170527

25. Guimei M, Fikry FE, Esheiba OM. Patterns of violence against women in three communities in Alexandria, Egypt. MCN Am J Matern Child Nurs. 2012 Sep;37(5):331-8. PMID:22895206

26. Haddad LG, Shotar A, Younger JB, Alzyoud S, Bouhaidar CM. Screening for domestic violence in Jordan: validation of an Arabic version of a domestic violence against women questionnaire. Int J Womens Health. 2011;3(3):79-86. PMID:21445377

27. Global and regional estimates of violence against women: prevalence and health effects of intimate partner violence and non-partner sexual violence. Geneva: World Health Organization; 2013.

28. Ghosh N, Mohit A, Murthy RS. Mental health promotion in post-conflict countries. J R Soc Promot Health. 2004 Nov;124(6):268-70. PMID:15602995

29. Donaldson, RI et al. Injury burden during an insurgency: the untold trauma of infrastructure breakdown in Baghdad, Iraq. Journal of Trauma and Acute Care Surgery, 69(6), 1379-1385.

30. Bishai D, Bachani A. Injury costing frameworks. In: Li G, Baker SP, editors Injury research:theories, methods, and approaches. New York, Spinger Science Business Media, LLC; 2012.

31. Jacobs G, Aeron-Thomas A, Astrop A. Estimating global road fatalities. Crowthorne, U.K.: Transp Res. Lab; 2000.
32. Blincoe, LJ et al. The economic impact of motor vehicle crashes, 2000 (No. HS-809 446,). Washington, DC: US Department of Transportation, National Highway Traffic Safety Administration. May, 2002.

33. Elvik R. How much do road accidents cost the national economy? Accid Anal Prev. 2000 Nov;32(6):849-51. PMID:10994613

34. Connelly LB, Supangan R. The economic costs of road traffic crashes: Australia, states and territories. Accid Anal Prev. 2006 Nov;38(6):1087-93. PMID:16797462

35. Rezaei, S et al. Extent, consequences and economic burden of road traffic crashes in Iran. Journal of injury and violence research, 2013, Jan 5(1): 1-10.

36. Guidelines for estimating the costs of road crashes in developing countries. Final Report, London: Department for International Development, 2003. (http://www.transport-links.org/ transport_links/filearea/documentstore/105_R\%207780. PDF, accessed 24 August, 2014)

37. Benmaamar M. Urban transport services in Sub-Saharan Africa: Improving vehicle operations. Sub-Saharan Africa Transport Policy Program. The World Bank and Economic Commission for Africa; 2003 (SSATP Working Paper No. 75) (http://www.ssatp.org/sites/ssatp/files/publications/SSATPWorkingPapers/SSATPWP75.pdf, accessed 24 August 2014)

38. Bakaitis SH Economic consequences of traffic accidents in the Baltic countries. Lithuanian Quarterly Journal of Arts and Sciences. 2000 Fall;49(4) (http://www.lituanus. org/2000/00_3_05.htm, accessed 24 August 2014)

39. Zhou Y, Baker TD, Rao K, Li G. Productivity losses from injury in China. Inj Prev. 2003 Jun;9(2):124-7. PMID:12810737

40. Costs of intimate partner violence against women in the United States. Atlanta: Centers for Disease Control and Prevention; 2003 (http://www.cdc.gov/violenceprevention/ pdf/ipvbook-a.pdf, accessed 26 April, 2014)

41. Nectoux M, Mugnier C, Baffert S, Albagly M, Thélot B. Evaluation économique des violences conjugales en France [An economic evaluation of intimate partner violence in France]. Sante Publique. 2010 Jul-Aug;22(4):405-16. PMID:20858339

42. Niebuhr D, Salge S, Brzank P. Kosten Intimer Partnergewalt gegen Frauen. Ein systematischer Review [Costs of intimate partner violence against women. A systematic review]. Bundesgesundheitsblatt Gesundheitsforschung Gesundheitsschutz. 2012 May;55(5):715-27. PMID:22526861

43. Joshi SK, Shrestha S. Economic and social burden due to injuries and violence in Nepal: a cross-sectional study. Kathmandu Univ Med J (KUMJ). 2009 Oct-Dec;7(28):344-50. PMID:20502072

44. Bonomi AE, Anderson ML, Rivara FP, Thompson RS. Health care utilization and costs associated with physical and nonphysical-only intimate partner violence. Health Serv Res. 2009 Jun;44(3):1052-67. PMID:19674432

45. Fang X, Brown DS, Florence CS, Mercy JA. The economic burden of child maltreatment in the United States and implications for prevention. Child Abuse Negl. 2012 Feb;36(2):156-65. PMID:22300910

46. Mock CN, Gloyd S, Adjei S, Acheampong F, Gish O. Economic consequences of injury and resulting family coping strategies in Ghana. Accid Anal Prev. 2003 Jan;35(1):81-90. PMID:12479899

47. Hawamdeh ZM, Ibrahim AI, Mezher AA. Traumatic brain injury in the Gaza Strip: adults and children and their caregiver disability burden. Eur J Phys Rehabil Med. 2011 Jun;47(2):193-201. PMID:21150858

48. Herbert HK, Hyder AA, Butchart A, Norton R. Global health: injuries and violence. Infect Dis Clin North Am. 2011 Sep;25(3):653-68, x. PMID:21896365 
49. Mehio Sibai A, Sameer Shaar N, el Yassir S. Impairments, disabilities and needs assessment among non-fatal war injuries in south Lebanon, Grapes of Wrath, 1996. J Epidemiol Community Health. 2000 Jan;54(1):35-9. PMID:10692960

50. Norton R, Hyder AA, Bishai D, Peden M. Unintentional injuries. In: Disease control priorities in developing countries, 2nd edition. Jamison DT, Breman JG, Measham AR, Alleyne G, Claeson M, Evans DB, et al. Washington (DC): World Bank; 2006.

51. Peden, $M$ et al. ed. World report on child injury prevention. Geneva, Switzerland: World Health Organization UNICEF. 2008

52. Wesson HK, Boikhutso N, Bachani AM, Hofman KJ, Hyder AA The cost of injury and trauma care in low- and middle-income countries: a review of economic evidence. Health Policy Plan. 2013 Oct 4 [Epub ahead of print] PMID:24097794

53. Tan-Torres Edejer T, et al., editors. Making Choices in Health: WHO Guide to Cost-Effectiveness Analysis. Geneva, World Health organisation, 2003 (http://www.who.int/choice/ publications/p_2003_generalised_cea.pdf, accessed 26 April, 2014)

54. Bishai DM, Hyder AA. Modeling the cost effectiveness of injury interventions in lower and middle income countries: opportunities and challenges. Cost Eff Resour Alloc. 2006;4:2. PMID:16423285

55. Bishai D, Asiimwe B, Abbas S, Hyder AA, Bazeyo W. Costeffectiveness of traffic enforcement: case study from Uganda. Inj Prev. 2008 Aug;14(4):223-7. PMID:18676779
56. Chisholm D, et al. Cost effectiveness of strategies to combat road traffic injuries in sub-Saharan Africa and South East Asia: mathematical modelling study. BMJ. 2012 Mar 2;344:e612.

57. Ditsuwan V, Lennert Veerman J, Bertram M, Vos T. Costeffectiveness of interventions for reducing road traffic injuries related to driving under the influence of alcohol. Value Health. 2013 Jan-Feb;16(1):23-30. PMID:23337212

58. Rahman F et al. Cost-effectiveness of an injury and drowning prevention program in Bangladesh. Pediatrics 2012; 130:e1621-8.

59. Jan S, Ferrari G, Watts CH, Hargreaves JR, Kim JC, Phetla G, et al. Economic evaluation of a combined microfinance and gender training intervention for the prevention of intimate partner violence in rural South Africa. Health Policy Plan. 2011 Sep;26(5):366-72. PMID:20974751

60. Norman R, Spencer A, Eldridge S, Feder G. Cost-effectiveness of a programme to detect and provide better care for female victims of intimate partner violence. J Health Serv Res Policy. 2010 Jul;15(3):143-9. PMID:20308226

61. Shibru D, Zahnd E, Becker M, Bekaert N, Calhoun D, Victorino GP. Benefits of a hospital-based peer intervention program for violently injured youth. J Am Coll Surg. 2007 Nov;205(5):6849. PMID:17964444

62. Al-Kharusi W. Update on road traffic crashes: progress in the Middle East. Clin Orthop Relat Res. 2008 Oct;466(10):245764. PMID:18704613 